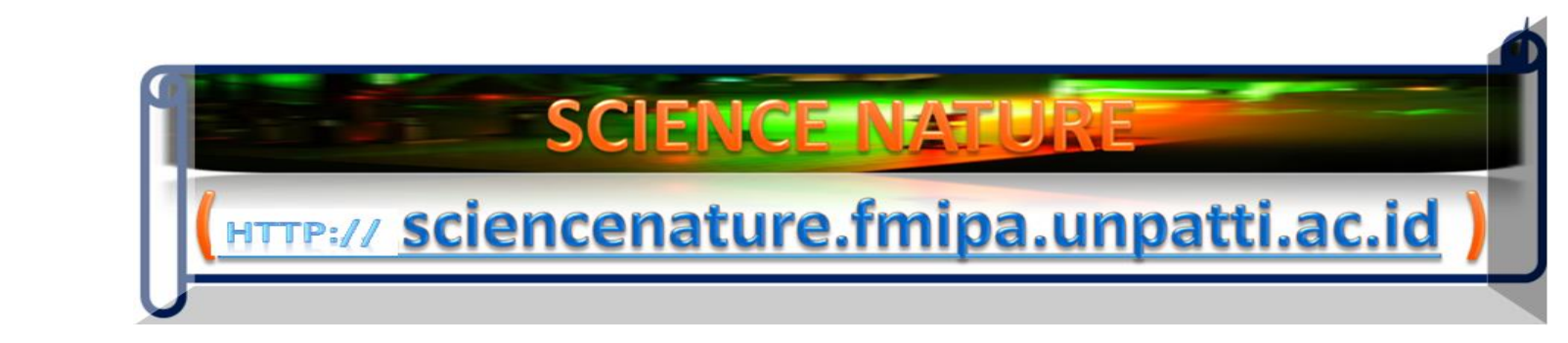

Science Nature 2(1), pp.086-089 (2019)

e-ISSN: 2654-6264

DOI: https://doi.org/10.30598/SNVol2Iss1pp086-089year2019

\title{
Nanochip Medicine: Physical Chemistry Engineering
}

\author{
Hendry Izaac Elim (Elim Heaven $)^{1-7 *}$ and Long Y. Chiang ${ }^{8 \#}$ \\ ${ }^{1}$ Specific Laboratory of Electronics and Instrumentation (ELINS lab), Physics Department, \\ Faculty of Mathematics and Natural Sciences (FMIPA), \\ Pattimura university, Indonesia 97233 \\ ${ }^{2}$ Nanomaterials for Photonics Nanotechnology Laboratory (N4PN Lab.), Department of \\ Physics, FMIPA, Pattimura University, \\ Jl. Ir. M. Putuhena, Poka, Ambon, Indonesia 97233 \\ ${ }^{3}$ Nanotechnology Research Center and Innovative Creation (PPNRI-LEMLIT), Research \\ Center of Pattimura University, Pattimura University Campus, Jl. Mr. CHR. Soplanit, \\ Rumah Tiga, Ambon, Indonesia 97234 \\ ${ }^{4}$ Multidisciplinary Research Center of Excellence (MrCE), \\ UNPATTI, Jl. Chr. Soplanit, RumahTiga, Ambon, Indonesia 97234 \\ Jl. Ir. MartinusPutuhena, Poka, Ambon, Indonesia 97233 \\ ${ }^{5}$ Maritime and Marine Science Center of Excellence (MMSCE) \\ Jl. Dr. Leimena, Ambon, Indonesia 97234 \\ ${ }^{6}$ Theoretical Physics Laboratory, Physics department, Pattimurauniversity, \\ Ambon, Indonesia 97233 \\ ${ }^{7}$ Development and Innovative Center (PPI) of Pattimura University, Indonesia \\ ${ }^{8}$ Department of Chemistry, University of Massachusetts Lowell, Lowell, USA 01854
}

Received : March 22, 2019

Revised : March 28, 2019

Published : March 30, 2019

Copyright @ All rights are reserved by H.I. Elim (Elim Heaven) and L.Y. Chiang

Corresponding author: "Email: hendry.elim@staff.unpatti.ac.id; "Email: Long_Chiang@uml.edu 


\section{Abstract}

In providing the best nanocarbon-based medicine particularly associated with their multitasking healing system, an advanced knowledge and understanding of physical chemistry engineering is compulsory. Discovery of the first spherical nanocarbon cage $C_{60}$, namely, fullerene or buckyball by R. Smalley and his colleague in $~ 1986$ at Rice university made the former elected as a chemistry Nobel laureate 10 years later in 1996. Various investigations in conjunction with fullerenes had been tremendously pursued in many interesting research fields, especially, on its characters including nonlinear and optical limiting behaviors, ultrafast dynamics of electrons in 5-level models, and advanced theoretical and computational cooperation system involving fullerenes encapsulated in a carbon nanotube (CNT). This present editorial communication stimulates an alternative view of physical chemistry engineering of fullerene and its derivatives functioning as nanofullerene-based medicine and its potential healing impacts. Our aims focus on the use of such non-toxic nanocarbons for various broad application leading to a number of different medicinal products.

Keywords: Nanofullerenes, Medicine, Physical chemistry, Engineering.

\section{EDITORIAL}

The idea of advanced nanotechnology development $[\mathbf{1 , 2}]$ has been well-developed in this $21^{\text {st }}$ century engineering system. Many nanoscience, nanomedicine, and nanotechnological products have been implemented in various applications, particularly, in prominent engineering system, pharmaceutical breakthrough drugs, and society educational tools. Recently, multitasking herbal medicine system has been introduced and fabricated based on physical chemistry engineering techniques [3-7]. Furthermore, fullerene or bucky-ball as the first nanocarbon was fabricated by a molecular composition consisting of 60 integrated carbon atoms in a spherical cage structure of $\mathrm{C}_{60}$. It was found to be

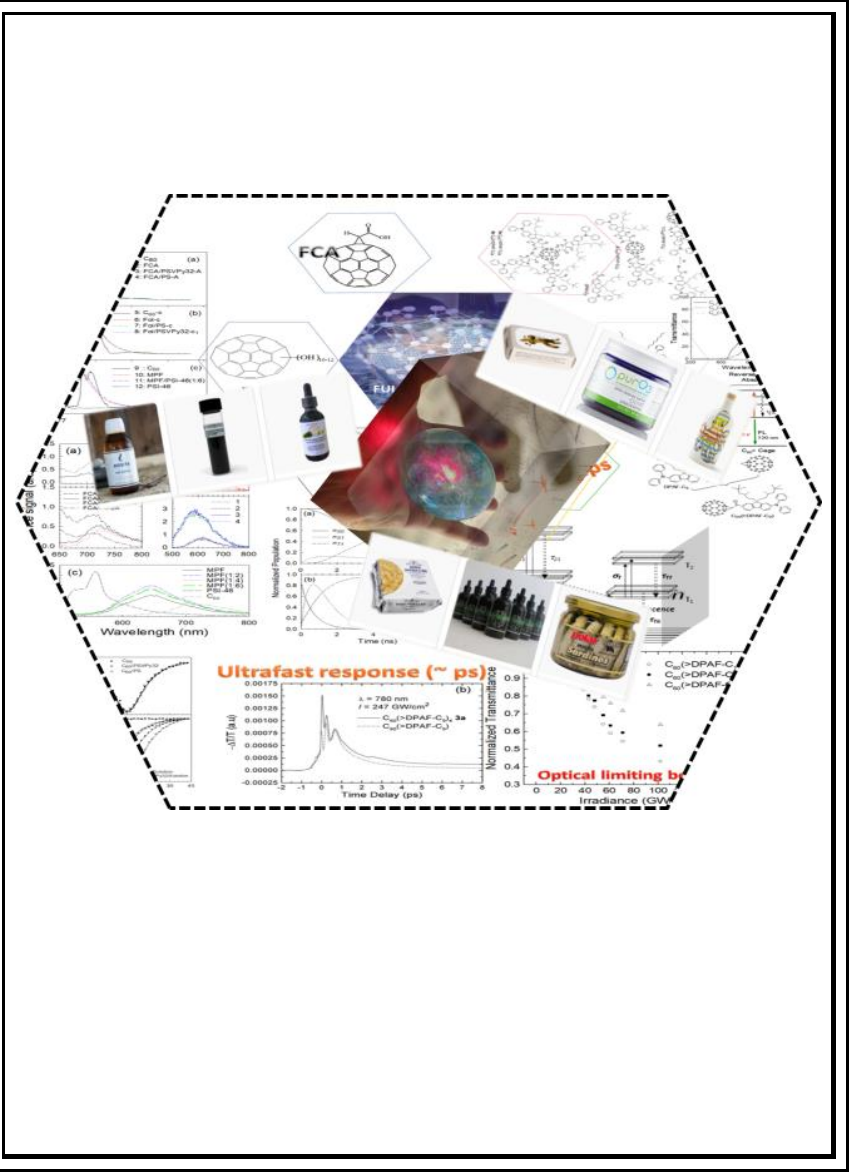

nontoxic and in a cage size of $\sim 1.0 \mathrm{~nm}$ in diameter. There were ongoing research efforts, especially, using attractive conjugative derivatives as molecular components in optical limiting devices and the ultrafast telecommunication system, as described in Fig. 1. On the other hand, fullerene-based nanomedicines are recently applied as key ingredients in various food products, such as olive oils, crackers, and even expensive inks. These are illustrated and highlighted in the graphic abstract of this editorial paper.

Figure 2 displays many different efforts $[\mathbf{1 , 6 - 8}]$ conducted in the past one decade on the method and approach to improve optical characters of fullerenes by incorporating covalent attachments of single, multiple, or complex branches. As light-matter interactions are much more sensitive in quality responses with just a small amount of energy necessary to detect and react to certain 
types of properties, such as electricity and magnetism, as well as healing system in injured or damaged human cells and membranes. In addition, by understanding the physical chemistry engineering the injection of fullerene-based medicine into human vein and body, impacts on its healing system can be obviously identified.

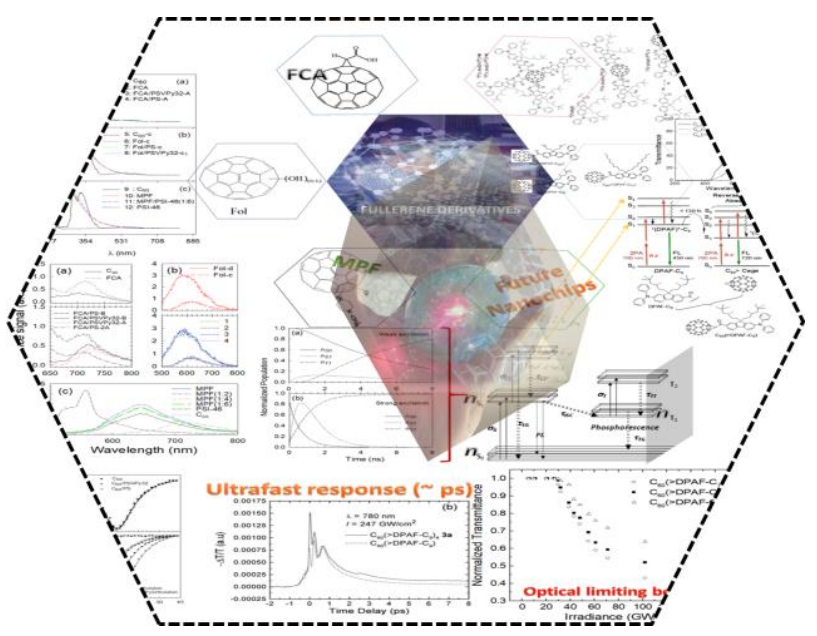

Figure 1. Multitasking system of fullerene and its derivatives chips: from the view of physical chemistry engineering. .

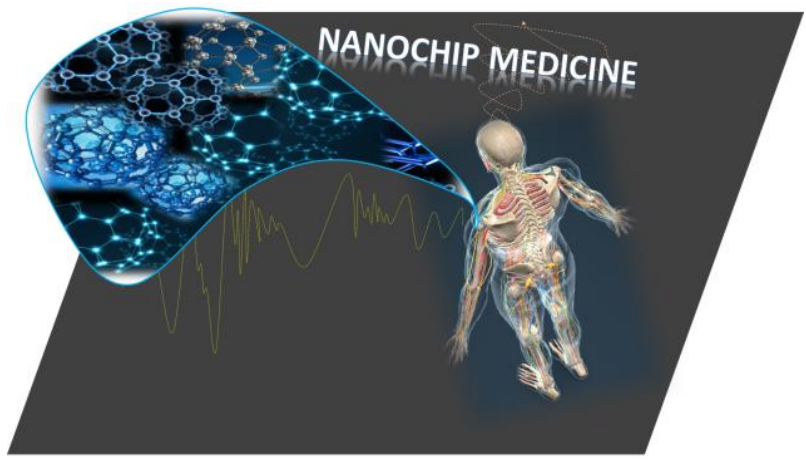

Figure 2. Dynamics of nanomedicine in human body: an illustration of its flowing, interactions and healing system.

In Fig. 2, the nanofullerene-based medicine indicates that incorporating nanocarbons, via oral uptake, into human vein with the molecular size ratio of $\sim 1 / 1000$ smaller than the inner vein diameter may have circulated without any changes from its original structure from its entrance from human mouth to the pass motion output. As a matter of fact, even the fullerene-based medicine is not toxic in a mixture with olive oil, crackers or another types of foods, the healing system is still unclear. We suggest a further detail study being necessary in order to uncover its mystery

In conclusion, a brief point-to-point discussion of medicine based nanofullerenes has been enlightened. The physical chemistry engineering of the compound suggests a further investigation needed in its process inside human body.

\section{Acknowledgement}

H.I.E work was partly supported by a world class research (WCR) grant from Indonesia Ministry of Higher Education (Ristek-Dikti) from this year of 2019 to 2021 entitled as "Nanotechnology Storage Mobile NanoBattery (SMN-B) for Future Energy Sources."

\section{References}

[1]. H.I. Elim, Nonlinear Optics and The Frontier of Nanoscience and Nanotechnology, Pattimura University Press, pp. 1-144 (2018). ISBN: 987-602-61906-9-7.

[2]. H.I. Elim, THE FIRST 1000 ATOMS IN HEALING PROCESS: FROM NANOTECHNOLOGY TO NANOMEDICINE, IJHMCR 3 (04), 1044-1046 (2018).

[3]. H.I. Elim, Multitasking Herbal Nanomedicine: A Frontier Report, Nanoscale Reports 2 (1), 22-30 (2019).

[4]. H.I. Elim, Scientific Breakthrough Based on Natural Creation: "1 Diamond with 7 Eyes", COJ Reviews and Research 1 (1), 1-4 (2018).

[5]. H.I. Elim, Theory, Implementation and the Nature of Truth (TIN) in Nanoscience, Nanotechnology, and Nanomedicine (NNN): From the Beginning of Universe to nm Scale Behavior, Kenkyu Journal of Nanotechnology \& Nanoscience 5, 33-36 (2019).

[6]. H. I. Elim, Sea-Ho Jeon, Sarika Verma, Wei Ji, Loon-Seng Tan, Augustine Urbas, and Long Y. Chiang, Nonlinear Optical Transmission Properties of $\mathrm{C}_{60}$ Dyads Consisting of a Light-Harvesting Diphenylaminofluorene Antenna, J. Phys. Chem. B Letters 112, 9561-9564 (2008).

[7]. H. I. Elim, Jianying Ouyang, Suat Hong Goh, and Wei Ji, Optical limiting based materials of mono-functional, multi-functional and supramolecular C60-containing polymers, Thin Solid Film 477, 63-72 (2005). 
[8]. H.I. Elim, Robinson Anandakathir, Rachel Jakubiak, Long Y. Chiang, Wei Ji and Loon-Seng Tan, Large concentration-dependent nonlinear optical responses of starburstiphenylamino-fluorenocarbonyl methano[60]fullerene pentads, J. Mater. Chem. 17, 1826 (2007).

\section{*/\#Corresponding Authors Brief CV:}

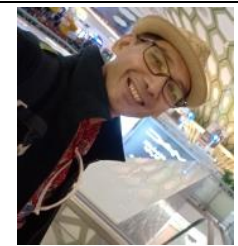

${ }^{*}$ Assoc. Prof. H.I. Elim is a young Indonesia physicist from Pattimura university. He has contributed many breakthrough works on physical behaviors of light-matter interactions of various novel nanomaterials in the field of nanoscience, nanotechnology and nanomedicine for more than 15 years. His deep knowledge and understanding have been marked by over 66 international high impact papers and proceedings with $h$ index of $\sim 23$ based on web of science (WOS, Thompson Reuter) and citation more than 2220. By developing the first laboratory of nanomaterials for photonics nanotechnology (Physics department of Faculty of Mathematics and Natural sciences, http://fisika.fmipa.unpatti.ac.id/n4pn) in the end of 2014, and nanotechnology research center and innovative creation (http://lppm.unpatti.ac.id/pusat-pnri) on 24 th April 2015 at Pattimura university, he had educated over 60 research undergraduate physics students with various simple novel works related to superfibers of garbage materials, biohybrid membranes fabricated from natural rubbish products, and chemical physics properties of herbal medicines. Moreover, Prof. Elim has delivered various quest lectures and international talks both in national universities such as Universitas Negeri Manado, Universitas Sam Ratulangi, and Universitas Indonesia, as well as many different international conferences such as PharmaNano 2018 in Las Vegas and PharmaNano 2019 in New York.

\#Prof. L.Y. Chiang, a world prominent chemist at University of Massachusetts Lowell, Boston, USA. 